\title{
Oral morphine
}

Recent introduction of oral morphine, though only in its sustained release form, has initiated a new era in the field of cancer pain management and palliative care in Bangladesh. Opioids, are on the list of essential medicines for palliative care which was developed by the International Association for Hospice and Palliative Care (IAHPC) on request of $\mathrm{WHO}^{1}$. It has been rightly claimed that 'Palliative care anywhere can succeed only if these services can relieve severe pain; thus the adequate and continuous availability and correct use of opioids such as morphine is critically important' ${ }^{2}$. As in many developing countries, it is typical in Bangladesh that cancer is diagnosed in the very late stage when pain is prevalent and often severe ${ }^{3}$. Severe pain destroys a persons quality of life and dignity. Severe pain also affects families, neighbours and the community. A painful death leaves indelible marks in the developing countries where the person with cancer is often cared for in the community and at home $e^{4,5}$. In 1986, to address the problem of unrelieved pain due to cancer in the world, the World Health Organisation (WHO) announced a three step method for treating cancer pain that relied on the use of drugs such as morphine for severe pain ${ }^{6}$

It has been repeatedly acknowledged that governments have an obligation not only to prevent abuse, trafficking, and diversion of narcotic drugs, but also to ensure their adequate availability for medical and scientific purposes ${ }^{7,8}$. The International Narcotics Control Board (INCB), in cooperation with governments, endeavours to ensure that there is an adequate supply of these drugs for medical and scientific purposes and to limit their production and use only to such purposes. But ultimately, a number of barriers like legal restrictions, existing drug policy, lack of education and misconceptions amongst medical professionals as well as people in general hinder the availability of morphine sulphate for patients at the levels of supply, prescribing and dispensing.

It is gathered that INCB has allocated $350 \mathrm{~kg}$ pethidine, $100 \mathrm{~kg}$ morphine and $200 \mathrm{mg}$ of fentanyl for Bangladesh ${ }^{9}$. Oral morphine tablets became available for the first time in Bangladesh in 2006 when one pharmaceutical company was allowed to manufacture $1,98,530$ tablets, each with $15 \mathrm{mg}$ sustained release forms using $3 \mathrm{~kg}$ of morphine raw material. Of these, 1450 tablets were dispensed during the first year (2006-2007) which rapidly rose to 18000 during the next year (2007-2008) ${ }^{10}$. Understandably, this visible rise was in parallel with initiation and propagation of palliative care service in the country. Acknowledging growing rise in demand of the oral morphine at one end, it also needs to be emphasized that this consumption is only a tiny fraction of the actual requirement of the country.

In the face of this recent availability in morphine tablets, though in a very restricted and limited manner, years of frustrations are giving way to renewed hope and even enthusiasm that palliative care workers in Bangladesh may be able to have the morphine they need to relieve pain in the thousands of cancer patients.

The task does not end by making morphine, particularly the oral form available in the market . Education in its use is required at all levels. The physicians need to realize that pain of patients can be and must be relieved. Patients and their families need to be educated that it is their right to demand pain relief. Our society cares deeply about curing cancer and so we invest a great deal in prevention and treatment. How much do we care about the quality of life of people who live and die with cancer pain! For the majority of people of Bangladesh who remains below poverty line, it is the generic oral immediate release morphine which is obviously the cost effective 'gold Standard' drug of choice ${ }^{11}$.

Relief from pain is an act of extreme mercy. As Albert Schweitzer puts it "we all must die but that I can save a man from days of torture that is what I feel is my great and ever new privilege. Pain is an even more terrible lord of mankind than death itself" 


\section{Nezamuddin Ahmad}

Associate Professor \& Project coordinator, Palliative Care Service, Department of Anaesthesia, Analgesia \& Intensive Care Medicine, Bangabandhu Sheikh Mujib Medical University

(Journal of BSA, 2008; 21(2): 59-60)

\section{References:}

1. Radbruch L ,Foley K, De Lima L, Praill D, and Furst G J. International Association for Hospice and Palliative Care list of Essential Medicines for Palliative Care, Annals of Oncology 2007 18(2): 395 - 399

2. Joranson DE, Rajagopal MR, Gilson AM. Improving access to opioids analgesics for palliative care in India. Journal of Pain and Symptom Management, 2002; 24 (2): 152 - 159

3. World Health Organization. Cancer pain relief: with a guide to opioids availability. Second ed. Geneva, Switzerland: World Health Organisation, 1996

4. Sureshkumar K, Rajagopal MR. Palliative Care in Kerala, Pall Med 1996/10:293-298

5. Ajithakumari K, Sureshkumar K, Rajagopal MR, Palliative home care : The Calicut experience.Pall Med 1997;11:451-454
6. World Health Organisation. Cancer pain relief, Geneva, Switzerland: World Health Organisation 1986

7. International Narcotic Control board. Report of the International Narcotic Control Board for 1999. New York,: United nations, 2000

8 Report of the International Narcotic Control Board for 2001 United nations,2002

9. Shahidur Rahman, Additional Director, Narcotic department, Dhaka zone, Bangladesh Personal Communication

10. Certain observation and recommendation on Morphine Pethidine injections and morphine tablets. Report of narcotic department, Dhaka, Bangladesh 23-1- 08

11. Rajagopal M.R, David Mazza and Arthur G. Lipman. Pain and Palliative Care in The Developing World and Marginalized Populations: A Global Challenge. Journal of Pain and Palliative Care Pharmacotherapy. 2003: Volume 17, Numbers 3,4; 1-10. 